III Seminário Nacional Metropole: Governo, Sociedade e Território

\title{
A metrópole e a patrimonialização do território: a análise dos bairros de Santa Teresa (Rio de Janeiro) e Alfama (Lisboa).
}

Fabio Costa Peixoto 1

\section{Resumo}

A representação do passado das cidades, percebida na prática discursiva dos agentes sociais promotores e gestores do patrimônio histórico, tem sido construída em meio às disputas pelo sentido da história. O principal resultado desta associação permite constatar que a identidade local funciona como um elemento aglutinador na estruturação dos elos que criam um sentimento coletivo de pertencimento a uma comunidade frente aos processos desestabilizadores da globalização da sociedade contemporânea. Selecionamos o bairro de Santa Teresa na cidade do Rio de Janeiro e o bairro de Alfama, na cidade de Lisboa para tratar das questões atuais referentes à preservação do patrimônio urbano no que diz respeito às invenções das tradições, a criação de símbolos e às transformações identitárias, ou seja, na sua função de estratégia representacional. $\mathrm{O}$ imaginário instituinte que identifica o bairro com um nome, uma comunidade e quase um monumento histórico, é tensionado pela emergência de novas territorialidades e sociabilidades decorrentes de projetos de modernização das cidades.

Palavras-chave: memória, patrimônio, Lisboa e Rio de Janeiro

\section{Introdução}

"O patrimônio se situa entre a memória e a história". Jacques Le Goff, História e Memória.

Este artigo quer sugerir aos leitores uma abordagem crítica das múltiplas dimensões da construção do passado que, no plano do discurso, surge como detentor de valores que permeiam as classes sociais. Portanto, sugere uma apreensão plural da realidade social considerando os usos diferentes da memória e, consequentemente, as disputas entre as memórias coletivas como construções sociais imaginárias que orientam as ações de patrimonialização.

As discussões que iremos tratar neste artigo dizem respeito, em última análise, aos processos de patrimonialização marcados pela globalização em curso na 


\section{REVISTA TAMOIOS}

sociedade contemporânea. Os discursos atuais acerca da preservação, restauração e revitalização urbana são então tensionados pelas antinomias espaço-temporais da modernidade, ou, dito de outro modo, nenhuma cidade atualmente pode almejar construir um significado próprio por meio de seu patrimônio urbano sem considerar a força globalizadora que influencia e altera o curso da história local e global. Tal processo orienta, inegavelmente, as práticas sociais sobre um determinado espaço e desvela os bastidores do jogo do poder no campo da disputa econômica, política, cultural e simbólica que permeia a preservação do patrimônio.

Os discursos dos agentes sociais envolvidos nos processos de patrimonialização ainda são marcados pela certeza da existência de um patrimônio histórico insubstituível por memórias coletivas que encontram nos monumentos históricos que conformam a identidade dos lugares o referencial imagético das práticas e representações sociais. A noção de patrimônio nos remete tanto à memória quanto à história; a um território propriamente dito, real ou imaginado e, conseqüentemente, leva-nos a estabelecer os marcos da relação entre o tempo presente e o futuro que almejamos coletivamente. Os debates sobre a conservação dos bens patrimoniais indicam um movimento incessante de instrumentalização do passado, de criação de símbolos e, portanto, expressam visões plurais e estratégias políticas acerca da realidade social. Nesta perspectiva, o patrimônio urbano (na sua função de guardião da singularidade das cidades e de estratégia do desenvolvimento local) é uma representação desses ideais e adquire um lugar central na problematização dos processos societários contemporâneos.

Se "o passado é uma das dimensões mais importantes da singularidade", como afirmou Abreu (1998) ao analisar a valorização do passado das cidades, é nele que buscamos as origens das identidades sociais contemporâneas. Nesse anseio coletivo, a memória e a história constituem possibilidades de acesso ao passado. Não iremos, aqui, nos aprofundar nas distinções entre história e memória, e sim refletir sobre o sentido que o passado adquire para os indivíduos na contemporaneidade, sobretudo no que diz respeito à preservação do patrimônio urbano frente aos novos dinamismos econômicos e a própria transformação da identidade simbólica dos lugares. Nesta perspectiva, a memória coletiva, entendida como fruto das representações compartilhadas pelos membros de uma sociedade, 


\section{REVISTA TAMOIOS}

adquire preeminência na constituição do patrimônio histórico e de novas dinâmicas locais, traduzindo, conseqüentemente, novas identidades e novas sociabilidades.

Em síntese, podemos dizer que a memória marca a permanência das tradições e costumes de um determinado grupo social. A lembrança proporcionada pela memória permite aos sujeitos reencontrarem as imagens de seu passado, prolongando o passado no presente. Quando esta memória se enfraquece, quando desaparece o grupo que lhe deu suporte, entra em cena a história, sendo então necessário institucionalizá-la (daí os "lugares de memória”, de Pierre Nora). Por sua vez, a história procura construir uma memória total (da nação, por exemplo), ao passo que a memória é sempre plural e parcial. Enquanto a memória busca identidades, durações e origens, a história sempre se ocupa do novo, da ruptura e da descontinuidade, dessacralizando o passado. Como articular, criticamente, essas duas dimensões para o estudo da história e da memória das cidades?

O caminho já foi indicado: "para se tratar da memória de um lugar há que se trabalhar então na recuperação simultânea da história no e do lugar" (Abreu, 1998, p.19). Conseqüentemente este artigo é um esforço de empreender tal tarefa na recuperação da história e da memória do bairro de Santa Teresa no município do Rio de Janeiro em seu processo de patrimonialização. Nosso objetivo principal é perceber as manifestações das memórias coletivas, constituídas em torno de recortes do passado, sobre a conformação do atual patrimônio histórico, cultural e arquitetônico deste bairro carioca em uma perspectiva comparada se utilizando o caso do bairro de Alfama na cidade portuguesa de Lisboa. Ela será realizada a partir de um longo trabalho etnográfico realizado pela equipe de Antônio Firmino da Costa do Instituto Superior de Ciências do Trabalho e da Empresa (ISCTE) realizada ao longo dos últimos 20 anos. Por fim, percebemos que as estratégias de investimento associadas ao patrimônio urbano, além de revelar as forças sociais atuantes no campo das disputas pelo sentido da história, acabam redefinindo conceitos e concepções acerca da cidade, o que aponta para a necessidade de revisar as noções tradicionais de urbano. 


\section{REVISTA TAMOIOS}

\section{O patrimônio urbano}

Uma discussão sobre a questão do patrimônio é uma tarefa árdua principalmente pela necessidade de se considerar os variáveis presentes na definição do próprio conceito, ainda mais quando se consideram as dimensões histórica, cultural e arquitetônica. O grau de complexidade amplia-se exponencialmente quando se considera o papel que a memória social exerce nesta definição. Neste sentido, a memória coletiva adquire um papel importante, posto que, construída a partir de uma seletividade, torna-se também um resultado das disputas pelo sentido da história.

Para Ruben Oliven (2003, p.77), "o termo patrimônio - em inglês heritage refere-se a algo a ser preservado e que, por conseguinte, deve ser preservado". Nessa dimensão que contempla a herança material de determinada sociedade, preservar-se-á da destruição o conjunto dos bens arquitetônicos já não mais integrados nas nossas práticas cotidianas

Outra noção de patrimônio adotada por Nestor Canclini (1984, p.95) afirma que o "patrimônio não inclui apenas a herança de cada povo, as expressões 'mortas' de sua cultura, mas também os bens culturais visíveis e invisíveis", sugerindo "um patrimônio que expressa a solidariedade que une os que compartilham um conjunto de bens e práticas que os identifica, mas também costuma ser um lugar de cumplicidade social" (idem, p.97). Conseqüentemente, esta noção mais dinâmica de patrimônio está profundamente associada ao conceito de cultura, onde se inclui hábitos, costumes, tradições, crenças e um acervo de realizações materiais e imateriais.

Em decorrência destas duas noções, podemos sintetizar que: "o patrimônio [passou a ser utilizado] não apenas para simbolizar, representar ou comunicar, [ele] é bom para agir. Não existe apenas para representar idéias e valores abstratos e para ser contemplado. O patrimônio, de certo modo, constrói, forma as pessoas." (GONÇALVES, 2003, p.27).

Este aspecto "antropológico" do patrimônio salientado aqui funciona como um elemento que auxilia na estruturação dos elos que criam um sentimento coletivo de pertencimento comunitário e colabora para sedimentar o imaginário presente (...). Esse imaginário instituinte que identifica o bairro com um nome, uma comunidade 


\section{REVISTA TAMOIOS}

(como se verá ao longo desse trabalho) e quase como já foi dita um monumento histórico é tensionado pela emergência de novas territorialidades e sociabilidades decorrentes de projetos de modernização das cidades. Nesta perspectiva, infere-se que: "a noção de património urbano histórico constitui-se na contracorrente do processo de urbanização dominante. Ela é o culminar de uma dialética da história e da historicidade que se joga entre três figuras (ou aproximações sucessivas) da cidade antiga" (CHOAY, 2006, p.158).

Logo, esta noção adquire substância e peso ao se considerar ação de agentes sociais responsáveis pelo incentivo ao processo de patrimonialização em curso onde se destacam algumas questões estruturantes.

\section{A memória urbana}

Ao nos referirmos à memória, tratamos da memória urbana que é, de fato, o objeto que constitui o patrimônio histórico de Santa Teresa. Ao ampliar uma discussão ampla dos casos de Santa Teresa e Alfama e selecionamos oportunidades e caminhos visando a construção de uma análise que possa, a partir de um estudo comparativo, refletir sobre a existência de uma memória urbana e mais, em sua condição de um elemento agregador de um patrimônio urbano presentes em ambos os bairros. ABREU (1998) realizou uma discussão sobre o que seria a memória urbana onde esta foge a discussão clássica sobre memória social e se foca em torno do que ele denominou de memória das cidades. Por memória das cidades o autor entende o estoque de lembranças "eternizadas", frutos do passado que são perceptíveis na paisagem de um determinado lugar onde elas são reapropriadas por segmentos da sociedade. De posse desta definição, distinguiremos a memória das cidades de outra, a da memória urbana que, por sua vez, Maurício de Abreu conceitua como "o estoque de lembranças do modo de vida urbana per se, sem obrigação de relacioná-las a uma base material particular, a um lugar específico" (ABREU, 1998, p. 18). Ela é importante para a compreensão do papel da história no processo de resgatar a memória e, principalmente, os embates que decorrem do ato de resgatar o passado de um determinado lugar. 


\section{REVISTA TAMOIOS}

A história exerce, neste contexto, um relevante papel que é o de "desenterrar" o passado no entanto com um viés mais reflexivo, especialmente no que se refere à percepção mais ampla do processo histórico. Recuperando as distinções entre história e memória, é possível afirmar que a história, isoladamente, só consegue recuperar o passado, mas não o lugar, um lugar sempre repleto de vivências e cotidianidades. Esta incapacidade da história de recuperar o lugar é derivada de sua dedicação ao urbano que Abreu (1998, p.19) definiu como tendo "o referencial, o abstrato, o geral e o externo" e que, no entanto, apenas um olhar mais detido sobre a cidade poderia recuperar a importância pretérita do lugar, pois é a cidade que diz respeito ao particular, ao concreto e ao interno.

A tentativa de recuperação da história e a memória de Santa Teresa pode ser compreendida a partir do patrimônio encontrado em Santa Teresa. No entanto, a mesma se encaminha para reduzir uma discussão ampla dos casos de Santa Teresa e Alfama e selecionar oportunidades e caminhos visando a construção de uma análise que possa, a partir deste estudo comparativo, refletir sobre a existência de uma memória urbana que se constrói em um elemento agregador de um patrimônio urbano presente em ambos os bairros. Ele motiva retomar, mesmo que brevemente, Maurice Halbawachs, em sua importância de conferir valor ao espaço como receptáculo da memória coletiva.

O espaço socialmente construído é signo da permanência das tradições, da continuidade das relações afetivas nele investidas. Segundo o autor, "o tempo da memória só se concretiza quando encontra a resistência de um espaço" (HALBWACHS, 1990, p.150). Este espaço seria a cidade, pois ela seria capaz de conferir aderência ao ligar os indivíduos, famílias e grupos sociais conferindo à memória um processo de cristalização na figura de seu patrimônio histórico, cultural e arquitetônico.

A presença da materialidade do espaço reforça um sentimento de segurança e estabilidade, imprescindíveis à memória coletiva dos grupos sociais. Em Santa Teresa é o caso do Castelo do Valentim, o Parque das Ruínas e a antiga Casa de Laurinda Santos Lobo. Esse conjunto arquitetônico citado inclui os principais prédios do bairro bem como os três principais espaços públicos - os largos do Curvelo, dos Guimarães e das Neves - e importantes locais de sociabilidades e como um acervo 


\section{REVISTA TAMOIOS}

um imenso "valor patrimonial" (COSTA, 2005) que funciona como uma das principais atratividades do bairro.

Observando o caso de Alfama, notamos referências em torno de um patrimônio arquitetônico datado do inicio de sua ocupação entre os séculos II a.C e V d.C entre a encosta do Castelo até o rio Tejo, no núcleo do primeiro povoamento de Lisboa. Logo, a reflexão sobre o bairro de Alfama nos leva a considerar a história e mais, o processo de formação de uma cidade como Lisboa.

Então, analisaremos o bairro de Alfama utilizando-o como o ponto de partida para vôos mais longos como o de se pensar a própria cidade de Lisboa. O bairro de Alfama se caracterizou ao longo da ocupação muçulmana (entre os séculos $\mathrm{V}$ e VIII) ${ }^{2}$ período onde se concentrou um considerável número de judeus representado pela própria Rua da Judiaria. No entanto, a retomada da cidade pelos cristãos no século XII, o bairro passou a se transformar em uma típica localidade composta principalmente por pescadores e outros indivíduos que trabalham em atividades afins. Este perfil se manterá durante as primeiras décadas do século $\mathrm{XX}$, quando ele sofre uma pesada intervenção do Estado principalmente em sua dimensão simbólica.

O resgate do valor patrimonial do bairro como um todo, percebido por muitos como um museu a céu aberto, suscita uma questão relevante que diz respeito à ausência de uma utilização sustentável de seu patrimônio, tendo em vista o acentuado processo de depredação do seu acervo. A ineficácia das estratégias de preservação adotadas gerou um impasse em torno de como preservar, contrapondo de um lado, os órgãos responsáveis por esta tarefa e, de outro, os proprietários dos imóveis a serem preservados.

O patrimônio pode ser pensado através da ótica da invenção da tradição que indica um processo social de luta simbólica em torno do que deve ser preservado. Os debates atuais reproduzem a lógica de mercantilização da cultura que, no caso de Santa Teresa, atualmente tem significado a vocação para o turismo. A premissa da "invenção das tradições" permite compreender a noção de patrimônio histórico como construção social. Este processo é perpassado por uma idéia de "patrimônio genuíno" que indica uma seleção 


\section{REVISTA TAMOIOS}

"de entre os inúmeros possíveis, focalizando de maneira privilegiada esta ou aquela época, este ou aquele elemento arquitectónico ou urbanístico, no conjunto virtualmente inesgotável de todos os que foram sendo construídos e destruídos, refeitos e modificados, num processo permanente, ao longo da história" (COSTA, 2005, p.34).

Nesta perspectiva, a antiguidade torna-se um indício para se conferir "autenticidade histórica" ao que se pretende classificar como patrimônio histórico, cultural e arquitetônico. Ela só é possível através do emprego da antiguidade aliado à memória, seja ela urbana ou coletiva. Esta última fixa a memória de uma forma mais ampla, posto que é viva e eque esta vivacidade é fruto de sua própria definição apontada por Halbawachs (1990, p.42) como sendo "um conjunto de lembranças construídas socialmente e referenciadas a um conjunto que transcende ao indivíduo". Este reforço da coletividade se apresenta através da valorização que concebe o autor do "caráter familiar, grupal, social da memória".

Ao analisarmos alguns elementos do patrimônio histórico, cultural e arquitetônico de Santa Teresa propomos recuperar a história e a memória assim como a de Alfama, onde percebemos a presença de "instituições de memória" materializadas na paisagem e no cotidiano daquele lugar. Desta forma, estas instituições também auxiliam no processo de constituição da identidade do lugar, especialmente na instrumentalização dos usos da história e da memória. Assim, a associação entre "instituições de memória" e uma consolidada identidade local conferem ao bairro um potencial favorável a investimentos voltados principalmente para o turismo.

No que se refere às disputas pela preservação, também é importante destacar a existência de "memórias coletivas" identificadas em segmentos da classe média e alta e outra, nos segmentos populares. Elas são construções motivadas pelo fato de "ser impossível recuperar a memória de uma cidade em sua totalidade de memórias coletivas que tiveram a cidade como referencial" (ABREU, 1998, p.15) e que reflete na intensa luta simbólica, envolvendo os diversos grupos sociais que habitam o bairro. 


\section{A construção da identidade local}

Costa (2005) empregou o conceito de "sociedade de bairro" para compreender os fenômenos societários que ocorrem no bairro português de Alfama, na cidade de Lisboa, e do qual também nos servimos para pensar as novas sociabilidades do bairro carioca de Santa Teresa. Ao adotarmos este referencial para compreender os processos responsáveis pela construção identitária local, além de encontrarmos grandes semelhanças entre esses bairros, também percebemos que a noção de bairro torna possível a idéia de pertencimento e, conseqüentemente, a de comunidade.

A noção de bairro foi historicamente construída a partir de um processo de invenção, como nos diria HOBSBAWM \& RANGER (1984), por componentes da esfera pública, principalmente a municipal, para fins administrativos ${ }^{3}$ e para delimitação do território, geralmente alvo de intensas disputas, pois possibilitava a posse ou não de poder político a nível local. O bairro então adquire centralidade, que, anteriormente, era exercida pela vila reforçada pela sua caracterização a partir do binômio interior/exterior em relação ao bairro.

Esta relação manteve-se e passou a singularizar o bairro através de relações entre protagonistas sociais situados dentro e fora do bairro, práticas entre ele e outros espaços, processos de comunicação e de formação de representações simbólicas efetuados como resultado de relações entre segmentos da população residente e outros agentes sociais externos ao bairro.

Os elementos que tornaram possível uma comparação entre Alfama e Santa Teresa foram: a malha urbana, o caráter materialmente fechado destes bairros (os inúmeros becos, as escadinhas e vielas apertadas) e a impregnação da vivência cotidiana pelas formas locais de identidade coletiva arraigados nestas localidades. Em ambos os casos, a topografia é acidentada, divergindo apenas na localização dos bairros em relação à proximidade com o centro da cidade. No caso de Alfama, a sua localização está distanciada do centro enquanto Santa Teresa fica nos arredores do centro financeiro, possuindo até duas saídas no próprio centro da cidade. No que se refere aos outros elementos, os dois bairros possuem mais similitudes do que diferenças, principalmente devido à topografia em ambas as 


\section{REVISTA TAMOIOS}

regiões ser composta por morros, e também em relação à complexidade das identidades coletivas.

Como conseqüência deste processo, o bairro ganha espaço como local de convivência e onde as relações cotidianas são construídas e se fortalecem, pois elas são formadas a partir de um sentimento de pertencimento, seja por ser o local de nascimento ou de moradia, seja por uma mera pertença de caráter afetivo ou via relacionamento com os moradores do bairro.

As relações de vizinhança se constituem em um importante instrumento societário que gerou uma nova coletividade permeada por várias redes de relacionamento social que atravessam o bairro. Conseqüentemente, a proximidade exercida pela vizinhança, mesmo contrariando a dificuldade de acesso via automóvel, aliado a diversos atrativos paisagísticos e simbólicos, acabm por incentivar a vontade de permanência de famílias de classe média e alta que ainda representam $70 \%$ da população do bairro. Estas famílias contribuem para a construção de processos interlocais, ou seja, "aqueles que estabelecem relações entre subconjuntos populacionais e espaciais da cidade", estimulando "dinâmicas de constituição recíproca de identidades colectivas enquanto 'bairros' e num jogo de demarcações e inclusões identitárias” (COSTA, 2005, p.112-113), e que funcionam como um instrumento de conexão entre os diversos grupos sociais distribuídos na cidade, tanto no que se refere ao critério de divisão social quanto ao critério de ocupação do território.

Além das questões envolvendo o bairro e a idéia de vizinhança, a noção de "comunidade" se apresenta como uma forma de compreender a complexidade existente em Santa Teresa que, ao mesmo tempo em que é raro em uma cidade como o Rio de Janeiro, decerto a caracteriza como um bairro singular no contexto atual da cidade. Alfama também sofreu um intenso processo de patrimonialização principalmente com a intervenção do Estado Novo português. Esta intervenção é fruto do que Antônio Firmino da Costa denominou de "tese de manipulação". Esta tese pode ser compreendida como um enorme investimento simbólico na busca do que o Estado Novo chamou de "História de Portugal" e do "povo português" em um processo bem semelhante ao ocorrido no Brasil. Então é possível afirmar que o bairro de Alfama, como o conhecemos hoje é fruto de uma intensa agência simbólica 


\section{REVISTA TAMOIOS}

que resultou na criação da "aldeia mais portuguesa de Portugal" (COSTA, 2008, p.32).

Este processo levou a uma "referida estratégia de investimento simbólico, de caráter patrimonializante e folclorizante, teve de se confrontar, no seio de elementos afectos ao Estado Novo, com outras perspectivas, mais visadas para a demolição do bairro e conseqüente renovação urbana no local" (COSTA, 2008, p.36), o que aponta para uma nova questão, aquela entorno de uma representação social como nos diria Lefebvre.

Ao indicar para este caminho, podemos traçar paralelos bem interessantes visando dar continuidade a nossa análise. No caso de Santa Teresa, duas importantes representações sociais, sendo que uma delas foca a sua atenção no patrimônio arquitetônico e cultural do bairro, encontramos grande semelhança com o caso de Alfama.

Esta semelhança se torna evidente no caso de Alfama ao associar uma relação simbólica entre espaço e a história da cidade de Lisboa de uma forma muito emblemática do que no caso de Santa Teresa e do Rio de Janeiro.

As representações sociais presentes em Alfama e Santa Teresa se cristalizam na figura que Antônio Firmino da Costa denominou como "valor patrimonial". Em relação a Alfama, ele afirma que o valor patrimonial está localizado no conjunto arquitetônico como um todo e é onde encontramos uma incrível semelhança com Santa Teresa em torno de um conjunto urbano e um estonteante visual da bacia do rio Tejo e da Baía de Guanabara.

Esta noção é utilizada como referencial analítico por Zygmunt Bauman (2003) quando o autor analisa a vertente comunitária na sociedade contemporânea permeada por processos globais de deslocamento societário e que alteram as tradicionais estruturas societárias até então em vigor. Desta perspectiva, a noção de comunidade evidencia-se em Santa Teresa assim como o bairro de Alfama que possui uma singularidade baseada no fato dele ser um representante típico de uma cidade com um passado extenso e rico como é o caso de Lisboa. Esta possui uma homogeneidade bem maior que aquela encontrada em Santa Teresa, fato observado por Antônio Firmino da Costa, o qual ele denominou como sociedade de bairro, no qual: 
"se geram formas de identidade cultural especificamente assentes nas relações sociais locais e inscritas no cerne dos padrões culturais que, impregnando de modo constitutivos dessas relações sociais em toda a sua espessura, deles continuamente emergem." (COSTA, 2008, p.81).

Esta diferença em relação a estes formatos societários nos permite supor que, no caso de Alfama, se tornaria mais favorável a articulação dos diversos agentes sociais presentes no bairro, a partir do patrimônio e de uma identidade coletiva, em prol de uma resistência contra o processo de revitalização em curso.

Ao considerarmos 0 sentimento de pertencimento, especialmente ao considerarmos a valorização de um determinado "modo de vida" existente no bairro e que já constatamos ser uma representação social, uma "imagem urbana" e que também funciona como recurso potencializador de uma identidade coletiva que marca a singularidade de Santa Teresa assim como em Alfama.

Logo, a afirmação de COSTA (2005) de que uma teoria geral da comunidade considera um nível específico de integração social, dado através de laços de vizinhança, de cooperação acentuada, auxilia-nos na compreensão do fenômeno comunitário existente em Santa Teresa, onde a noção de comunidade é aquela concebida por Bauman ${ }^{4}$. As reflexões acerca de Alfama constataram a existência de fortes princípios comunitários que fornecem indícios que nos possibilitam afirmar a existência de uma comunidade no melhor estilo baumaniano onde encontramos também um paralelo num outro conceito do mesmo autor o de "comunidade perdida". Costa, ao considerar as profundas transformações sociais da modernidade, em particular no decorrer do século $X X$, deduz que o novo modo de vida urbano, cujo cenário tradicional foi marcado pelas grandes metrópoles, tende a extinguir as comunidades tradicionais e, em especial, as de bairro.

Este conceito também guarda uma enorme similitude em relação às considerações formuladas por BAUMAN (2003). O autor, em sua reflexão sobre os princípios norteadores da comunidade, possibilitou uma melhor compreensão de uma das conseqüências do processo de modernização que tenderia a extinguir as comunidades tradicionais. Destacamos o princípio de pertencimento a um determinado grupo, seja devido à proximidade espacial, seja por afinidades de interesses sociais, culturais e políticos específicos (e denominados habitus por Pierre Bourdieu). 


\section{REVISTA TAMOIOS}

Desse modo, podemos dizer que o bairro de Santa Teresa e o bairro de Alfama constituíram-se em autênticas comunidades, ainda que possuíssem mais de um habitus (identificados na diferenciação social entre as classes média e alta e das comunidades de baixa renda). Mesmo ambos sendo extremamente distintos, conseguem construir um sentimento de pertencimento mais amplo como se o bairro fosse uma "instituição" agregadora de diversos segmentos sociais distintos e ainda mais, como se fosse possível tirar o foco das contradições típicas do modo de produção capitalista.

Esta noção de comunidade apresentada por Bauman é fruto de uma concepção tradicional de constituição de agregação social que tenderia a ser substituída pelo conceito de identidade. Entretanto, olhar mais apuradamente sobre esta noção nos permite indicar alguns caminhos que podem auxiliar na tarefa de compreender melhor a relação entre comunidade/identidade.

Ao analisarmos o caso do bairro de Santa Teresa, percebemos que os princípios comunitários auxiliam na construção e na manutenção da identidade espacial ali existente. E, de certa forma, é possível incluir, em segundo plano, as diferenças sociais fruto de hierarquias sociais. Esta associação é reforçada por uma distinção que é "compartilhada por um grupo ou categoria de indivíduos suficientemente numerosos e determinados para merecer consideração (...) pois ela se tornam uma reivindicação coletiva (BAUMAN, 2003, p.71) que se apresenta e se solidifica através de diversas esferas e exemplos.

A nível de ilustração, citamos um fato ocorrido durante o carnaval 2007 como expressão do fenômeno societário "comunidade" presente em Santa Teresa. O Bloco das Carmelitas, a partir deste carnaval, decidiu não divulgar o horário em que o bloco sairia nos dois dias programados. O motivo alegado para tal atitude foi o excesso de foliões que acompanhavam o bloco. Tal decisão foi tomada para reduzir o número de participantes em uma tentativa de retornar a tempos em que apenas os moradores do bairro participavam dele Deste modo, "a defesa do lugar [é] vista como condição necessária de toda segurança, devendo ser uma questão do bairro, um "assunto comunitário" (...) podendo a comunidade - ser uma comunidade local, ou seja, uma comunidade corporificada num território habitado por seus membros e ninguém mais" (BAUMAN, 2003, p.102). 


\section{À Guia de Conclusão}

Após apresentarmos alguns elementos constituintes da identidade coletiva do bairro de Santa Teresa e de Alfama como as noções de "pertencimento", "bairro" e "comunidade" que, de certa forma, auxiliaram na tarefa de compreender a identidade ali existente, bem como seu processo de patrimonialização, podemos tecer algumas considerações.

Para facilitar a exposição de algumas conclusões preliminares, analisaremos aquelas que se apresentaram em Santa Teresa e posteriormente aquelas encontradas em Alfama. Em Santa Teresa, percebeu-se a presença de uma "genuína" identidade coletiva, considerando esta "genuinidade" como fruto da representação do passado histórico e, conseqüentemente, de patrimônio histórico, cultural e arquitetônico do bairro. Assim, a constituição da identidade local se relaciona diretamente com o "nascimento" e desenvolvimento inicial da cidade. Entretanto, esta identidade coletiva não é o resultado de uma homogeneidade social, mas sim resultado de distinções sociais que são expressas através de hierarquias e de conflitos sociais. No entanto, os atores tem logrado superar este empecilho, constituindo uma sólida identidade coletiva, o que necessariamente não ocorre em todas as unidades sócio-espaciais locais. Elas só são possíveis graças a uma determinada configuração social com referentes significativos de sentimentos de pertença, permitindo a criação desta identidade. Mas cabe ressaltar que esta identidade local não gera necessariamente um sentimento de pertença pautado em atributos sociais reportados ao território, nomeadamente a vizinhança residencial onde pelo contrário, a noção de vizinhança é percebida apenas no interior dos dois principais segmentos sociais do bairro.

Mas, para efeitos de uma identidade que possa ser exteriorizada para além das fronteiras do bairro e para explícitos fins de atividades turísticas, ela enunciaria os padrões culturais desta população e seus reflexos como uma representação simbólica do bairro como "entidade coletiva". Logo, a identidade local reforçada pela identidade cultural se torna partilhada, assim como ocorre na manutenção de um conjunto de atributos fundamentais, quer em sua amplitude no bairro e em sua intensidade com que ela é experimentada, quer nos conteúdos afetivos e cognitivos 


\section{REVISTA TAMOIOS}

e relacionais nela investido, quer ainda nas formas simbólicas e nas práticas sociais em que se exprime. Conseqüentemente, se constata a presença de estratégias identitárias que são, contudo,

estratégias sociais que encontram na identidade cultural do bairro as condições de sua emergência, de estratégias sociais que recorrem de maneira explícita a identidade cultural [que no caso de Santa Teresa funciona] como uma referência privilegiada e argumento da legitimação dos processos desencadeados e, ainda mais, de estratégias sociais que utilizam os ingredientes relacionais e simbólicos desta identidade cultural como instrumentos centrais dos modos concretos de ação coletiva (COSTA, 2005, p.480).

Elas são ainda capazes de gerar condições para uma agência transformadora apta a ser portadora da resistência frente a processos econômicos globais. Assim, o mais importante a ser ressaltado deste processo é a capacidade da identidade cultural de gerar efeitos sociais potencializadores de elementos básicos para a formação de protagonismos coletivos que possam romper com o intenso conflito que emergiu na esfera social e política do bairro de Santa Teresa.

Ao se referir sobre Alfama, notamos a presença de um forte sentimento comunitário associando uma idéia de pertencimento Entretanto, os elementos que geradores deste sentimento são distintos daqueles encontrados em Santa Teresa. Em Alfama, encontramos uma considerável homogeneidade social, o que nos permite afirmar a existência de um habitus dominante e significativo no bairro que o caracteriza como um bairro tipicamente popular, composto por trabalhadores em atividades portuária e de pesca, e de trabalhadores semiespecializados.

Outra característica que ressalta a o habitus local é a presença de moradores com um tempo considerável de permanência no bairro chegando a passar de antigas gerações para as atuais auxiliando na solidificação da identidade local no bairro. O fado, típica dança portuguesa, se torna um dos elementos que fortalecem o bairro e sua identidade, possuindo diversos locais para a prática da dança se constituindo em um dos pontos turísticos do bairro.

A organização dos moradores do bairro é de se destacar quando mencionamos Alfama na figura da Associação do Patrimônio e da População de Alfama que representa como aponta o próprio site da associação: "a organização dos moradores antigos e novos, em uma postura crítica e atenta no processo de reabilitação 


\section{REVISTA TAMOIOS}

urbana, o que nos possibilita afirmar que esta associação nos fornece indícios para uma organização intensa dos moradores em prol desta causa, o que reforça a presença de uma intensa identidade local”.

Ao observamos atentamente dois casos, Santa Teresa e Alfama notamos uma série de pontos convergentes e divergentes no que se refere aos processos em curso no espaço social destes bairros.

Sobre as convergências podemos assinalar a existência de um enorme patrimônio histórico construído em ambos os casos como resultado de uma longa história no caso de Santa Teresa a partir do século XVIII e em Alfama, a partir do século $\mathrm{V}$ a.C, período em que tiveram um intenso processo de patrimoniailzação gerada por processos semelhantes, aqui pelo Estado Novo português nos anos 1930 e pela ação do Estado e do capital "imobiliário-financeiro" ${ }^{5}$.nos primeiros anos do século XXI, no caso de se a Santa Teresa.

Já sobre as divergências, podemos apontar para a composição social dos bairros; os principais elementos da identidade local e o principal "atrativo locacional" encontrado em ambos os casos.

Alfama é caracterizado por uma considerável homogeneidade social, fato comprovado da maioria de seus habitantes estarem alocados em atividades de pesca e portuária, o que facilita enormemente a criação de uma identidade local incentivada por uma enorme integração social existente no bairro. Já em Santa Teresa, a heterogeneidade social dificulta a formação e a manutenção de uma identidade local, esta é reforçada por um rico e extenso patrimônio histórico e uma forte idéia de pertencimento.

O principal elemento estruturador da identidade local é o patrimônio histórico, como o fado, considerado sibilo nacional pelos portugueses, enquanto que em Santa Teresa, o principal elemento é um "modo de vida" típico do Rio Antigo, onde o patrimônio histórico é um elemento central neste processo.

E por último, em Alfama, o principal atrativo é a prática do fado, que simboliza, de certa forma, Portugal como nação e no caso de Santa Teresa, é o turismo, seja ele cosmopolita, seja ele reforçado pelo patrimônio histórico, cultural e arquitetônico. 


\section{REVISTA TAMOIOS}

Concluindo, a contraposição de experiências societárias tão distintas como Santa Teresa e Alfama apenas confirma a importância de se analisar espaços sociais díspares que em alguns aspectos guardam enormes similitudes como a origem e a identidade local. Então, a apresentação destes temas em casos como os de Alfama e Santa Teresa nos fornecem novos caminhos e discussões em campos como a da cultura e do desenvolvimento, por exemplo.

$\mathrm{E}$, como último ponto deste artigo, urge mencionar os temas tratados neste texto serem cruciais para a construção de uma agência política capaz de enfrentar processos amplos e desestruturadores dos modos de vida locais como é a globalização em seus mais diversos aspectos.

\section{Notas}

1 - Bacharel e Licenciado em Ciências Sociais pela UERJ, Especialista em Sociologia Urbana pela UERJ e Mestre em Planejamento Urbano e Regional pelo IPPUR/UFRJ e Docente do Instituto Federal de Educação Técnica e Tecnológica do Sul de Minas - Campus Inconfidentes.

2 - O peso da influência da permanência muçulmana na cidade se nota através do próprio nome de Alfama, que advêm de Al-Hama, que significa águas quentes ou fonte termal

3 - No caso carioca, a primeira divisão existente foi a de freguesias, que se dividiam em urbanas e rurais, no período do século XVI até o final do século XIX. Deste momento até 1918, a categoria freguesia suburbana foi adotada para designar regiões que possuíam ambas as características. A partir de 1918, foi adotada a divisão da cidade por zonas: urbana, suburbana e rural, permitindo a formação de unidades menores conhecidas como bairros, que devido ao intenso crescimento demográfico e de complexidade social, fomentaram a criação dos mesmos, locais onde indivíduos possuem raízes e onde se encontram, em diversos níveis, imersos em uma comunidade.

4 - Comunidade: a busca por segurança no mundo atual

5 - Grifo do autor 
Referências Bibliográficas

ABREU, M. Evolução Urbana do Rio de Janeiro. Rio de Janeiro: IPLAN-RIO / Editora Zahar, 1987.

Sobre a memória das cidades. Revista Território, ano III nํ 4, jan. / jun 1998.

BAUMAN, Z. Comunidade: A busca por segurança no mundo atual. Rio de Janeiro: Jorge Zahar Editor, 2003.

BOURDIEU, P. O poder simbólico. 7ª ed, Rio de Janeiro: Bertrand Brasil, 2004.

CANCLINI, N. G. O patrimônio cultural e a construção imaginária do nacional. Revista do Patrimônio Histórico Artístico Nacional, no 23, 1994, p.94-115.

CHOAY, F. A invenção do património urbano. In: A alegoria do património. Lisboa: Edições 70, 2006, p.155-179.

COSTA, A. F. Sociedade de bairro - dinâmicas da identidade cultural. Lisboa: Editora Celta, 2005.

GONÇALVES, J. R. S. O patrimônio como categoria de pensamento. In: ABREU, R. e CHAGAS, M. (orgs). Memória e patrimônio: ensaios contemporâneos. Rio de Janeiro: DP\&A Editora, 2003, pp.21-29.

HOBSBAWM, E. \& TERRANCE, R. A invenção das tradições. Rio de Janeiro: Editora Paz e Terra, 1984.

LE GOFF, J. História e Memória. 4ae ed., Campinas, SP: Editora da Unicamp, 1996.

NORA, P. Entre Memória e História: a problemática dos lugares. Projeto História, no 10, dezembro de 1993.

OLIVEN, R. Patrimônio intangível: considerações iniciais. In: ABREU, R. e CHAGAS, M.(orgs). Memória e patrimônio: ensaios contemporâneos, Rio de Janeiro: DP\&A Editora, 2003, pp.77-80.

Sites consultados

www.patrimonioalfama.pt 